\title{
Source Apportionment of Urban Road Dust Using Four Multivariate Receptor Models
}

Jithin Jose

Vellore Institute of Technology: VIT University

SRIMURUGANANDAM B ( $\boldsymbol{\sigma}$ bsrimuruganandam@vit.ac.in )

Vellore Institute of Technology: VIT University https://orcid.org/0000-0003-1324-5552

\section{Research Article}

Keywords: Road dust, Receptor model, Source apportionment, Resuspended dust, Elemental composition

Posted Date: August 4th, 2021

DOI: https://doi.org/10.21203/rs.3.rs-163837/v1

License: (c) (1) This work is licensed under a Creative Commons Attribution 4.0 International License. Read Full License 


\title{
Source Apportionment of Urban Road Dust using Four Multivariate Receptor Models
}

\author{
Jithin Jose and B. Srimuruganandam* \\ School of Civil Engineering, \\ Vellore Institute of Technology, \\ Vellore - 632 014, Tamil Nadu, India. \\ E-mail: bsrimuruganandam@vit.ac.in; pauljithinjose@gmail.com \\ Telephone: 91-416-2202169, Fax: 91-416-2243092. \\ *Corresponding Author
}

Abstract

Road dust is one of the biggest contributors to airborne particulate matter (PM) in many urban regions. Due to the inherent heterogeneity of road dust, it is important that its sources are identified and mitigated. Multivariate receptor models are used for source apportionment of PM in many cities. In recent years, these receptor models are finding more applications outside the scope of PM source apportionment. In this study, four multivariate receptor models (Unmix, Positive Matrix Factorization, Principal Component Analysis and Multiple Curve Regression) are used for source apportionment of road dust at Vellore City, India. The elemental composition of road dust samples from 18 locations and for three seasons (summer, winter, and monsoon) are measured using acid digestion followed by Inductively Coupled Plasma - Optical Emission Spectroscopy. Irrespective of models, results showed that crustal material $(100 \%-68 \%)$ and resuspended road dust $(82 \%-15 \%)$ are the biggest contributor to road dust in the study region. Brake wear, tire wear, biomass combustion, vehicular emission and industrial sources are some of the other sources identified by the receptor models. Receptor modeling performance of MCR and PCA models are unsatisfactory. PMF and Unmix models gave acceptable results. From comparing the performance characteristics, Unmix is found to be the ideal receptor model for this dataset. This research clarifies the constraints of different receptor models and the source apportionment information obtained is critical for development of future policy and regulation.

Keywords: Road dust; Receptor model; Source apportionment; Resuspended dust; Elemental composition. 


\section{Introduction}

31 Chemometric methods of data analysis is a cornerstone for air pollution control in urban

32 environments (Azid et al. 2015). Isolating and quantifying the contribution of various sources to

33 pollution at a location is one of the most common applications of chemometrics in environmental

34 data. This is commonly referred to as receptor modeling (Devi and Yadav 2018). Receptor

35 modeling started gaining popularity during the mid-2000s and continues to be a major player in

36 urban air quality management (Zhang et al. 2017). These models reconstruct the contribution of

37 individual sources to pollution in a region using the ambient pollutant concentration information

38 (Henry et. al., 1984) and are frequently used for source apportionment of particulate matter (PM)

39 emissions (Heo et al. 2009).

Road dust is consistently seen in source apportionment studies irrespective of study location (Belis et al. 2014). Road dust is the loose, mostly crustal material settled in road surfaces that is resuspended by the action of wind or wake from vehicular movement (Abu-Allaban et al. 2003; Amato et al. 2009). Combustion and non-combustion vehicular emissions such as exhaust emissions, tire wear, brake wear and engine wear are the common source of road dust in urban environment (Denby et al. 2018). Non-vehicular sources of road dust include crustal material transported by wind (Mao et al. 2013), construction and demolition activities (Marín et al. 2011)

47 and street sweeping (Amato et al. 2010). The heterogenous nature of road dust impacts human 48 health necessitating effective qualitative and quantitative apportionment of the sources. This 49 information is needed to develop effective control and mitigation strategies to reduce morbidity 50 from exposure to road dust (Bartkowiak et al. 2017).

Toxicological studies have noted that these sources of road dust can release dangerously high 52 amounts of potentially toxic elements (PTEs) (Arslan 2001) and polycyclic aromatic hydrocarbons 
53 (PAH) (Khpalwak et al. 2019). Many of these chemicals are also classified as "probably

54 carcinogenic to humans" by the International Agency for Research on Cancer (IARC 2020).

55 Studies show that children are at a greater risk of being exposed to high concentration of PTEs and

56 PAH since they spend a greater portion of their day outdoors (Zeng et al. 2019). Developmental

57 disorders like impaired mental development (Isaac et al. 2012) and stunted growth (Zeng et al.

58 2019) are common in children exposed to elevated concentrations of PTEs.

Source apportionment of PM is studied extensively in research from around the world

60 (Banerjee et al. 2015). However, application of these receptor models in source apportionment of

61 road dust have garnered considerably less attention. Cities in developing countries tend to see even

62 fewer studies. This is alarming because many of the world's most polluted cities are in developing

63 countries, especially in South Asia. Vellore is a small tier - 2 city (MHRD 2015) in the South

64 Indian state of Tamil Nadu. The city is spread over a land area of $87.92 \mathrm{~km}^{2}$ and has a population

65 of 177,230 (as per 2011 Census). For a semi-arid land locked city like Vellore, road dust is a major

66 cause of concern. In this study, the results from four receptor models are compared viz., Unmix,

67 Positive Matrix Factorization (PMF), Principal Component Analysis - Multiple Liner Regression

68 Analysis (PCA-MLRA), and Multiple Curve Regression - Alternating Least Squares (MCR-ALS).

69 The major objectives of this study are, (1) Identifying and apportioning the sources of road dust in

70 the city, thereby helping future endeavors in regulation and policy, (2) Recognizing the constraints

71 of different receptor models used in this study, and (3) Most importantly, this research could prove

72 to be instrumental in reinvigorating receptor modeling studies on road dust.

\section{2. Methodology}


Figure 1 shows the sampling region and sampling locations. Deposited dust samples from the road surface are collected from 18 locations within Vellore City. Table 1 shows the various sampling locations. More information on the sampling region is explained in Jose and Srimuruganandam (2020). Road dust samples are collected from $27^{\text {th }}$ and $28^{\text {th }}$ of January $7^{\text {th }}$ and $8^{\text {th }}$ April and $22^{\text {nd }}$ and $23^{\text {rd }}$ May of 2018 corresponding to Winter, Summer and Monsoon Seasons. Vellore city does receive summer rains towards the end of May and early June. The samples for monsoon season are collected towards the end of May a proxy for monsoon season since rains are unceasing during monsoon season, which makes it nearly impossible to collect samples. The samples for monsoon season were collected after two weeks of sporadic rains. Approximate weights of the samples were taken in situ using a generic weighing balance. The weighed samples are then sieved manually as per ASTM C136 (ASTM 2001). The portion of the sample that passed through $75 \mu \mathrm{m}$ sieve is subjected to microwave digestion using a mixture of $\mathrm{HCl}$ and $\mathrm{HNO}_{3}$ as per U.S.EPA 3050b procedure (U.S. EPA 1996) for direct energy coupling devices. The digested samples are analyzed for 25 elements (Ag, Al, As, Ba, Bi, Ca, Cd, Co, Cr, Cu, Fe, Ga, In, K, Li, Mg, Mn, Na, Ni, Pb, Rb, Se, Sr, Tl, Zn) by Inductively Coupled Plasma - Optical Emission Spectroscopy (Perkin Elmer, Avio - 200). Detailed information on sample collection, sample analysis and quality control can

91 be found in Jose and Srimuruganandam (2020).

\section{[INSERT TABLE 1]}

\section{4}

\subsection{Multivariate Analysis}

In this study, the efficacy of four different multivariate receptor models for source apportionment of road dust are examined viz., PCA-MLRA, Unmix, MCR-ALS, and PMF. 
PMF model is performed using pre-compiled binary available for Microsoft ${ }^{\circledR}$ Windows

operating system from U.S. EPA. EPA-PMF v.5.0 is used for this study. The software is run atop Microsoft $^{\circledR}$ Windows 10 (OS build 18363.836).

Pre-compiled binary for Unmix is available for Microsoft ${ }^{\circledR}$ Windows operating system from U.S.EPA. EPA-Unmix v.6.0 is used for this study. Since this binary is incompatible with modern operating systems, it is run in an Oracle VirtualBox virtual machine instance (1 logical processor and 1 GB RAM) on Microsoft ${ }^{\circledR}$ Windows XP (SP3).

MCR-ALS is performed using R, an open-source statistical modeling package (v.3.6.2) coupled with RStudio (v. 1.2.5) interactive development environment (IDE). ALS library available from the Comprehensive R Archive Network (CRAN) repository is used in this model.

Like MCR-ALS method, PCA-MLRA is done using R, (v.3.6.2) coupled with RStudio (v. 1.2.5) IDE. PCA and MLRA are done using functions available by default in R (prcomp and $\operatorname{lm}$ ).

All receptor modelling processes in this study are performed on a ThinkPad T430 Personal Computer (Intel Core i5- 3320M 2.60GHz, 8GB RAM). A brief explanation on various multivariate receptor models used in this study is given below.

\section{Theory of Receptor Modeling}

Receptor models are mathematical model that are used to identify and quantify the contribution of different sources of a pollutant at a receptor location. These models use the chemical composition of a pollutant at a receptor location to identify its sources. This is in stark contrast to sourceoriented models where the concentration at a receptor location is estimated if the properties of the source and meteorological conditions are known. The major advantage of using receptor model is that they use real measured ambient pollutant concentrations. 
119 Most receptor models work by factoring a large concentration data matrix into two lower rank

120 matrices. Since the number of samples are always greater than the number of variables, these

121 equations cannot be solved uniquely. Receptor models are used to obtain the best possible solution.

122 The difference between receptor models depends largely on the various approaches and constraints

123 employed by these models to get a valid solution (Henry 1991). Since the value of concentration

124 cannot be negative, non-negativity of mass concentration is a constraint used consistently in

125 receptor models (Belis et al., 2014). However, non-negativity alone is seldom enough for a

126 complete solution. Many other constraints are considered in modern receptor models like;

127 measurement uncertainty, factor rotation and multi-dimensional edge detection (Pant and Harrison

128 2012). In this study, source apportionment of road dust collected from Vellore city of South India

129 is studied by using different multivariate receptor models.

Meta-analysis of source apportionment conducted all over Europe show that the number of

131 receptor modelling studies is more than all other source apportionments methods combined (Belis

132 et al. 2014). Compared to other source apportionment methods, the location-first approach of

133 receptor modeling makes them ideal to assess the compliance of a receptor location to air quality

134 limits. Receptor-oriented models do not consider complex chemical and meteorological processes.

135 These models therefore have very modest computational requirements compared to source-

136 oriented models. Multivariate receptor models also negate the need for emission inventories thus

137 reducing uncertainties related to it (Hopke 2016). The inability of model reactive species limits the

138 use of receptor models to regional or urban scale. Application of receptor models necessitates the

139 availability of quantitative data at the receptor and demands good knowledge of the atmospheric

140 conditions and chemical nature of sources from the researcher. 
It is hard to establish a minimum number of samples in advance, since that number would

142 be dependent on the amount of information within the data set (Belis et al. 2014). Studies show

143 that at least 50 chemically characterized samples are needed to run multivariate analysis. (Johnson

144 et al., 2011). Other studies also mention that the number of samples should be approximately three

145 times the number of variables (Thurston \& Spengler, 1985). Also, small datasets from multiple

146 sites in a region are used in previous source apportionment studies (Xie et al., 2012). All

147 multivariate factor analysis works on the principle of matrix factorization (Hopke 2016). This can

148 be expressed mathematically by the expression.

$149 \quad C_{(m \times n)}=G_{(m \times p)} \times F_{(n \times p)}^{T}+E_{(m \times n)}$

where, the matrix $C$ is the concentration of $n$ elements collected at $m$ locations, $F$ is the factor

151 matrix with $n$ elements and $p$ factors, $G$ is the mass concentration matrix with $m$ observations and

$152 p$ factors. The matrix $E$ has information on the residuals from the model caused due to experimental

153 and measurement errors. Different receptor models apply different constraints to $F$ and $G$ matrices

154 to minimize the residuals in the $E$ matrix.

\section{3.1. Unmix}

156 The Unmix method is a multivariate model with built-in non-negative constraints. It begins with

157 singular variable decomposition (SVD) of the concentration matrix $C$ and is represented by the 158 equation below (Henry 2003).

$C_{i j}=\sum_{i=1}^{p} \sum_{k=1}^{p} U_{i k} D_{k l} V_{l j}+E_{i j}$

where $C_{i j}$ is the input data, $U$ and $V$ are orthogonal $n \times n$ and $m \times m$ matrices. $D$ is an $n \times m$

161 diagonal matrix. The Unmix model uses SVD to find the edges in an $m$-dimensional data space 162 and reduce the dimensionality of data from $m$ to $N$, where $\mathrm{n}$ is the number of sources identified. 
163 Equation 2 is like the general receptor model equation (Equation 1). The exception is that in normal

164 chemical mass balance approach, source composition is already known.

165 One of the major advantages of using Unmix model is that it has the non-negativity criteria 166 build into model. This negates problems arising from negative mass concentrations. Also, since 167 this model extracts all required constrains to solve the chemical mass balance equation from the 168 data itself, measurement uncertainties are not required to run this model. However, since the model

169 uses eigen vector analysis, it is not well suited for heteroskedastic data commonly seen in 170 atmospheric modeling.

\section{$171 \quad 3.2$. PCA}

172 PCA is an eigen vector method of matrix factorization that is used to reduce many possibly 173 correlated variables into a smaller number of uncorrelated principal components. In PCA method, 174 the total concentration of each element $i$ is assumed to be a sum of the elemental contribution from 175 the different elemental sources $j$. Thus, a normalized concentration matrix can be written as,

$176 \quad Z_{i k}=\sum_{p}^{j=1} W_{i j} P_{j p}$

177 Equation 2 can be rewritten in matrix terms as an analogue to equation 1 as,

$178 \quad[P]_{j \times \lambda}=[B]_{j \times i}[Z]_{i \times \lambda}$

This equation (3) is now equivalent to equation (1). The matrix $[\mathrm{P}]_{j x_{i}}$ is factorized based on 180 eigen value decomposition. Absolute Principal Component Scores are calculated by subtracting 181 an absolute zero principal component matrix from $[\mathrm{P}]_{j} x_{i}$ matrix as shown in equation (4) (Thurston 182 and Spengler 1985).

$183 \quad[\text { APCS }]_{p \times j}^{*}=[P]_{p \times j}^{*}-\left[P_{o}\right]_{p \times j}^{*}$ 

the APCS to total mass for each day as shown in equation (5).

186

$$
M_{k}=\zeta_{0}+\sum_{j=1}^{p} \zeta_{j} A P C S_{j k}^{*}
$$

Like Unmix, PCA model extracts all required constrains to solve the chemical mass balance equation from the data itself, measurement uncertainties are hence not used in this model. Also, PCA method does not require any specialized software. Many commercially available and opensource statistical packages have PCA model build into them. PCA is also an eigen vector decomposition method. Hence, the problems with heteroskedastic data haunts PCA. Unlike Unmix, PCA has no build in non-negativity constraints. This omission can lead to presence of negative mass concentration in source apportionment results. Although, PCA is generally not recommended for quantitative source apportionment, they can be used effectively for exploratory analysis.

\subsection{MCR}

MCR-ALS is a method used to recover pure response profiles of chemical components from an unresolved mixture without prior knowledge of its composition. This method is initially developed for gas chromatographs. However, this source apportionment is also a matrix factorization problem, MCR-ALS algorithm can be used. In the MCR-ALS model, the matrices $G$ and $F$ in equation (1) is calculated by minimizing the sum of squared residuals SSR (Tauler et al. 2009).

$S S R=\sum_{i=1}^{m} \sum_{j=1}^{n}\left(x_{i j}-\bar{x}_{i j}\right)^{2}$

In equation (6), $x_{i j}$ is the measurement of $j^{t h}$ element in the $i^{\text {th }}$ sample. Although this algorithm can work when both matrices are unknown, the problem can be further simplified by finding an 
205 initial solution using a simpler algorithm like simple-to-use interactive self-modeling analysis

206 (SIMPLISMA). Once matrix $F$ is initialized, matrix $G$ is calculated using:

$207 \quad G=X F\left(F^{T} F\right)^{-1}$

Non negativity in $G$ is obtained by minimizing the sum of residuals in matrix $X$ such that all

209 elements in matrix $G$ is greater than zero. This $G$ is then used to recalculate $F$ using:

$210 \quad F^{T}=\left(G^{T} G\right)^{-1} G^{T} X$

This iterative procedure continues until SSR value from two consecutive iterations fall below

212 a preset value.

Unlike PCA and Unmix model, MCR model use alternating least squares for solving the

214 chemical mass balance equation. Hence, this model is well suited for use in applications where

215 heteroskedastic data is analyzed. This model also has the advantage that non-negativity criteria is

216 built into it. All these advantages come at the cost of slightly higher computational requirements.

\section{3.4. PMF}

218 PMF is a purpose made receptor model that is developed by U.S. EPA for source apportionment 219 applications. The general working of PMF model is like MCR-ALS model with the exception that 220 the sum of squares of residuals SSR is minimized using the equation (Paatero and Tapper 1994):

$221 \quad S S R=\sum_{i=1}^{n} \sum_{j=1}^{m}\left[\frac{X_{i j}-\sum_{k=1}^{p} G_{i k} \cdot F_{k j}}{u_{i j}}\right]^{2}$

Like MCR-ALS model, PMF model is more suited for heteroskedastic data since it allows

223 individual weighing of data points. Usually, this model tends to resolve more sources than the 
224 other models tested here. The downside of this model is that it requires considerably higher

225 computational requirements compared to the other models.

\section{4. Results and Discussion}

227 Source apportionment is performed using the chemical composition of the collected silt samples

228 (fraction of road dust with size $<75 \mu \mathrm{m}$ ). Silt component of road dust is highest during the summer

229 season with $160 \mathrm{~g}$ for $1 \mathrm{~kg}$ of sample tested. This is followed by winter $(152.2 \mathrm{~g})$ and monsoon

230 season $(108.4 \mathrm{~g})$. The highest fraction of silt in road dust sample is at location 7 , near Vellore

231 district administrative office (264g). Being an administrative center, this location experiences

232 considerable vehicular traffic. The sampling location is also located below an overpass thus

233 impeding air movement. Lowest silt fraction is at location $1(88.37 \mathrm{~g})$ since this road has paved

234 sidewalks and is cleaned regularly. More information on chemical composition of analyzed road

235 dust and its seasonal variations is explained in Jose and Srimuruganandam (2020).

A total of six sources are identified by the four receptor models, viz., crustal material,

237 resuspended dust, tire and brake wear, biomass combustion, industrial sources, and vehicular

238 emission. Source apportionment by the individual receptor models is explained in more detail

239 below. It is to be noted that the sources are numbered for identification only and are not ranked in

240 by any means.

\section{4.1. Unmix}

242 For the Unmix model, 51 of the 52 observations are taken for consideration. One observation is

243 ignored (location 14 during winter season) to improve signal to noise ratio of the data. 100 feasible

244 solutions for unmix model are obtained from 218 runs. Run number 15 is chosen as the global

245 minima. The model identified five sources with a minimum $\mathrm{R}^{2}$ value of 0.93 and a minimum signal 
246 to noise ratio of 1.91. Source contribution of the five sources to different elements is shown in and

247 their contribution to different sources with different sampling locations is shown in Figure 2. The

248 scaled residuals are found to be between -3 and +3 .

\section{[INSERT FIGURE 2]}

\subsubsection{Source 1: Resuspended Dust}

251 The first source accounts for all the $\mathrm{Pb}$ present in road dust of Vellore city. It also shows significant 252 contributions to nearly all elements. It contributes least to $\mathrm{K}(5 \%), \mathrm{Mg}(5 \%), \mathrm{Mn}(8 \%)$, and $\mathrm{Sr}$ 253 (8\%). Low contribution to K would rule out biomass combustion as this source. High contribution 254 to $\mathrm{Pb}(100 \%), \mathrm{Rb}(22 \%)$ and $\mathrm{Li}(21 \%)$ suggests that this source could be resuspended road dust. 255 The probable source of $\mathrm{Pb}$ in this fraction could be from automobile exhaust prior to the year 2000; 256 when leaded fuel was banned in the country (Miguel et al. 1999; Das et al. 2018). Since lead halide 257 salts from vehicle exhausts are largely insoluble, they tend to remain in the environment for a long 258 time (Habibi 1970). From Figure 2, it is visible that the contribution of this source to pollution is 259 considerably high during the summer season. The semi-arid summers in the region are the reason 260 for increased resuspension of road dust. Winter season shows a relatively consistent contribution 261 of this source throughout the study region. However, there are clearly defined hotspots during 262 summer and monsoon. Highways are the most obvious hotspots of this source as evident from 263 locations 6, 8, 9 and 10. However the presence of $\mathrm{Pb}$ in location 14 can have other sources since 264 lead-acid battery refurbishment shops operate regularly in this region (Jose and Srimuruganandam 265 2020). 
267 Second source of road dust identified by Unmix shows significant contributions to almost all 268 elements in the study region. With high contributions going to $\mathrm{Al}(50 \%), \mathrm{Ba}(82 \%), \mathrm{Zn}(71 \%), \mathrm{Mg}$

269 (71\%), $\operatorname{Sr}(74 \%)$ and $\operatorname{Co}(55 \%)$. This source is expected to be a combination of both tire wear and 270 biomass combustion. High contribution to $\mathrm{K}$ and $\mathrm{Mg}$ show that biomass combustion could be a 271 contributor to this source (Pio et al. 2008). All other elements with high contribution from this 272 source suggest that tire wear is also a contribution to this source. $\mathrm{Zn}$ is a common tracer that is 273 used for identifying contamination from tire wear (Kupiainen et al. 2005). Studies have shown that 274 up to $1 \%$ of the tire tread material can be $\mathrm{Zn}$ (Councell et al. 2004). Co is added to the rubber 275 matrix to promote its adhesive characteristics (Fulton 2005), thereby improving the strength of tire 276 compound (Ooij 1984). Fluoride salts of Sr are used in some tire formulations for improving the 277 stability of resins (Yasuda et al. 1990). Magnesium alloys and forged aluminum are both used in 278 manufacture of engine blocks and pistons implying presence of engine wear in this source 279 (Lakshminarayanan and Nayak 2011).

This source is found to contribute heavily to road dust in locations 3, 17 and 18. This is 281 essentially a long stretch of road and thus tire wear can be a significant source of pollution in these 282 locations. Locations 3 and 18 are adjacent to gas stations. Barium from diesel fuel additives and 283 engine oil additives can also be contributing to the high levels of this source in these locations 284 (Monaci and Bargagli 1997). There is a considerable seasonal variation of this source. Winter 285 season shows the highest contribution whereas the monsoon season shows the lowest contribution.

287 The third source shows high contribution to Fe (27\%) along with a significant contribution to Al 288 (7\%), $\mathrm{Li}(14 \%)$ and $\mathrm{Cu}(8 \%)$ suggests that break wear can be a contributor to this source (Gramstat 289 2018). High contribution to Fe can be attributed to wear from brake disks and drums used in 
automotive braking systems (Garg et al. 2000; Kukutschová and Filip 2018). This source shows

291 high contribution throughout all three seasons. The highest contribution is noted during the

292 summer season. Winter season also shows a similar distribution for this source. Lowest

293 contribution for this source is noted during monsoon season since the brake dust could be washed

294 off during monsoons. Considerable spatial variation is not exhibited by this source.

\subsubsection{Source 4: Vehicular Emissions}

296 Fourth source shows significant contribution to $\mathrm{Cr}(66 \%), \mathrm{Ni}(58 \%), \mathrm{Mn}(47 \%), \mathrm{Ga}(45 \%)$ and $\mathrm{Cu}$ 297 (48\%). This suggests that the fourth source of road dust is possibly from vehicular emissions. 298 Source apportionment studies generally consider Ni as an indicator for oil combustion (Thomaidis 299 et al. 2003; Peltier et al. 2009). Studies show that heavy duty diesel engines can release significant 300 quantities of $\mathrm{Mn}$ (Hilden and Bergin 1986) and $\mathrm{Cu}$ (Konstandopoulos et al. 1988) since they are 301 used as fuel additives. Cr coating is used in high power diesel engine piston rings to prevent wear 302 (Rastegar and Craft 1993). Traces of these elements are also usually present in engine oils used by 303 diesel engines. From Figure 2 contribution of this source to road dust is maximum during the 304 summer season. Winter and monsoon show nearly equal distribution throughout the study region.

\subsubsection{Source 5: Crustal Material}

306 Fifth source shows high contribution only to Fe (19\%). Since Fe is one of the most abundant 307 elements on earth's crust (Turekian and Wedepohl 1961; Taylor 1964), it can be assumed that the 308 fifth source of road dust is crustal material. From Figure 2, contribution of crustal material to road 309 dust is minimal during the summer since vehicular emission and tire wear take a more prominent 310 place during this season. This source contributes high during the monsoon season. Rains during 311 monsoon season are expected to wash away pollutants from other sources. 
313 Microsoft Windows binary for EPA PMF 5.0 provided by U.S.EPA is used for the PMF model.

314 Of the 52 samples, 14 samples are discarded to improve the signal to noise ratio of the model

315 (shown as empty circles in Figure 3). The number of bootstrap runs is kept 100 with a minimum

$316 \mathrm{r}^{2}$ of 0.6 . The Q-robust of the model is found to be close to Q-true, suggesting that results are

317 acceptable. Scaled residuals for this model is between -7 and 7.

\section{[INSERT FIGURE 3]}

\subsubsection{Source 1: Vehicular Emission}

320 First source shows high loading only for $\mathrm{Ba}(57 \%)$. It is also seen to contribute moderately to Co,

$321 \mathrm{Sr}, \mathrm{Mg}$ and $\mathrm{Zn}$. The high loading of $\mathrm{Ba}$ indicates that this source could be vehicular emission.

322 Studies have shown that $\mathrm{Ba}$ is an effective indicator for vehicular emission (Monaci and Bargagli

323 1997; Monaci et al. 2000). Barium fuel additives are used extensively in diesel engines to reduce

324 smoke from combustion (Glover 1966; Truex et al. 1980). Barium fluoride is also used in some

325 engine oils to improve its load carrying capacity (Hermant et al. 1986). Monsoon season shows

326 the highest contribution from this source (Figure 3) since other sources of road dust could have

327 been washed away. Location 17 shows extremely high contribution during winter season.

328 Similarly, high contribution was also identified by Unmix model (Figure 2). This could be an

329 isolated incident like an oil spill.

\subsubsection{Source 2: Biomass Combustion}

331 Second source shows a high contribution towards K. This is indicative that this source could be

332 from biomass combustion. Potassium (Andreae 1983) and Levoglucosan (Achad et al. 2018) are

333 the two most common indicators for biomass combustion. This source shows higher contribution 
334 to road dust during the summer season due to the increased biomass load present in the road

335 surfaces. As expected, contribution from this source is found to be higher during summer season

336 and least during monsoon season (Figure 3). Contribution from this source is negligible during

337 monsoon season since damp vegetation inhibits combustion.

\subsubsection{Source 3: Resuspended Road Dust}

339 The third source shows considerable contribution to $\mathrm{Pb}(71 \%), \mathrm{Ni}(24 \%)$ and $\mathrm{Cr}(25 \%)$. It also

340 contributes to most other elements that are analyzed. High contribution to $\mathrm{Pb}$ would suggest that

341 this source is re-suspended road dust (Al-Chalabi and Hawker 1997; Wang et al. 2005). As stated

342 before, $\mathrm{Pb}$ based antiknock agents have been phased out of the country since 2000 (Sharma and

343 Pervez 2003). So, the contribution to $\mathrm{Pb}$ by this source can only be attributed to previously

344 deposited $\mathrm{Pb}$ two decades ago. As noted in the unmix model, the contribution of this source to road

345 dust in the region is greater during summer season due to the semi-arid conditions that are prevalent

346 in the city during summer.

\section{4.3.4. Source 4: Tire and Brake Wear}

348 Fourth source shows high concentration to $\mathrm{Cu}(54 \%), \mathrm{Zn}(29 \%), \mathrm{Cr}(44 \%)$, and Ni (50\%). Zinc is 349 an indicator for tire wear (Wang et al. 2005) and copper is seen more in brake wear particles 350 (Thorpe and Harrison 2008). As mentioned in previous models, Ni is an indicator for oil 351 combustion (Galbreath et al. 2000) and Cr can be linked to vehicular exhaust (Testa 2004). This 352 source can hence be concluded to be vehicular emission. From Figure 3 the contribution of this 353 source to the road dust in this region is greater towards the city center compared to the outskirts. 354 The increased traffic at this location can be the reason for this observation. Mean contribution from 355 this source is found to be greater during the winter season. Although tire wear generally increases 
356 during the summer season due to higher road temperature, the higher emissions from vehicle

357 exhausts and brake wear could have offset this.

\section{4.2.5. Source 5: Crustal Material}

359 The final source of road dust identified by PMF shows high contribution to Al (39\%), Ca (42\%),

$360 \mathrm{Fe}(44 \%), \mathrm{Mg}(38 \%), \mathrm{Sr}(44 \%)$ and $\mathrm{Co}(53 \%) . \mathrm{Fe}, \mathrm{Ca}$, and $\mathrm{Al}$ are the most abundant elements in

361 the earth's crust (Yaroshevsky 2006) suggesting that the fifth source is crustal material. This source

362 is found to contribute more to road dust during the winter season. The lowest concentration of road

363 dust is identified at the bridge across river Palar (Location no. 4). Higher contribution of sources

364 like tire and brake wear during summer season decreases the percentage contribution of crustal

365 material during summer season. Lower road temperatures during monsoon season coupled with

366 rains washing off smaller dust particles could be reason for high contribution of crustal material

367 (Figure 3).

\subsection{PCA-MLRA}

369 PCA model is run using a custom R script. All 52 samples are used in this model. Kaiser-Meyer-

370 Olkin (KMO) measure of sampling adequacy is 0.56 for the collected data. This suggests a factor

371 analysis can be performed with the data. Bartlett's test gave a significance level considerably lower

372 than 0.05 suggesting that the variables are related, and factor analysis can provide useful

373 information. Both the tests were performed using KMO and Bartlett test functions in 'psych'

374 library available at CRAN. With a cut off eigen value of 1, PCA can extract 5 principal components

375 (Table 2). The five principal components extracted accounted to $85 \%$ of the total variance. 
378 The first principal component accounts for $25 \%$ of the total variance explained by PCA. This

379 component shows high loading for $\mathrm{Al}, \mathrm{Sr}, \mathrm{Mg}, \mathrm{Cr}, \mathrm{Fe}$ and $\mathrm{Mn}$. The major source of these elements

380 in road dust is from crustal matter. $\mathrm{Al}$ and $\mathrm{Fe}$ are two of the most abundant elements present on

381 earth's crust (Rudnick et al. 2019). This source is found to contribute significantly to road dust in

382 the region throughout the year especially during the summer season (Figure 4). The dry summers

383 in the study region can be contributing to this. Major hot spots for this source are along roads that

384 lack a paved sidewalk or hard shoulders.

\subsubsection{Source 2: Biomass Combustion}

386 Second principal component accounts for $18 \%$ of the total variance and shows high loading for $\mathrm{K}$

387 and Li. High loading for K indicates presence of biomass (Yu et al. 2018). Hot spots for this source, 388 largely concentrated along Gandhinagar main road (locations 2, 3, 17 and 18) show that biomass 389 combustion has a higher contribution during monsoon season. This anomaly could be because 390 other sources could also be included in this principal component. Previous studies have noted the 391 presence of an unidentified source of $\mathrm{Li}$ in this region (Jose and Srimuruganandam 2020). 392 Locations towards the south of the city show contribution from this source during monsoon season, 393 which is in stark contrast to PMF model, where contribution from biomass combustion is largely 394 absent during this season.

\subsubsection{Source 3: Resuspended Dust}

396 Third component shows high loading for $\mathrm{Mg}, \mathrm{Sr}, \mathrm{Cr}, \mathrm{Cu}, \mathrm{Ni}$ and $\mathrm{Pb}$. This source accounts for $16 \%$

397 of total variance and contribute more during the winter season. High loading for Pb suggests that 398 the third source is from re-suspended road dust. Two of the biggest hot spots of re-suspended road 

$15)$.

\subsubsection{Source 4: Crustal Material}

402 Fourth principal component also shows high loading for $\mathrm{Ca}$ and Fe. Suggesting that this source is 403 also crustal in origin. This source contributes more to road dust during the winter season, with 404 contributions greater towards the south of city, suggesting that contribution from resuspended dust 405 might also be accounted in this source (Figure 2). This source has negligible contribution to road 406 dust during summer and monsoon seasons.

\subsubsection{Source 5: Tire Wear}

Fifth principal component accounts for $8 \%$ of the total variance. This component shows high loading for $\mathrm{Ba}, \mathrm{Cu}$ and $\mathrm{Zn}$. High loading for $\mathrm{Zn}$ and $\mathrm{Cu}$ suggests that the source is likely from tire wear (Kupiainen et al. 2005). Ba is usually present in vehicular emissions. The presence of $\mathrm{Ba}$ in suggests that this source could be a combination of both tire wear and vehicular emissions. This source has exceptionally low spatial variation and is distributed equally throughout the study region. As seen in Unmix and PCA models, contribution is higher during summer season and least during monsoon season (Figure 4). High vehicular traffic combined with impeded ventilation could be the reason for higher contribution of this source in location 7 (Figure 4).

\subsection{MCR-ALS}

The MCR-ALS model is run using the 'ALS' library provided by CRAN. For running the MCR model, an initial solution is necessary. This solution will help in reducing the number of iterations necessary before reaching a satisfactory solution. Since the SIMPLISMA model did not have an equivalent under CRAN, the results from the PCA model are used as an initial solution for the 
421 MCR-ALS model. The model converged in 14 iterations with non-negativity criteria for both

422 matrices. This model could extract only three sources from the receptor concentration data. The

423 deviation of data from ideal bilinear behavior can be the reason for poor source apportionment

424 results. The initial differential residual (RD) is 0.85 . After 14 iterations alternating between

425 optimizing S and C matrices, the RD value dropped below the default threshold of 0.001 . The

426 scaled residual in this model lies below \pm 3 .

\section{[INSERT FIGURE 5]}

\subsubsection{Source 1: Industrial Source}

429 The first source shows contribution to $\mathrm{Al}$ and $\mathrm{Mg}$. Presence of this source close to location 17 430 suggests that this source could be of industrial origin. There is an industrial estate towards east of 431 location 17 which can contribute to pollutants in this location. This source has a higher contribution 432 during summer and least contribution during monsoon season (Figure 5). Summer season shows 433 high contribution of this source in locations $1,2,4,5$ and 7 . Winter contribution is greater at 434 locations 2, 7 and 17. Contribution from this source must be studied further by dispersion modeling 435 methods.

\subsubsection{Source 2: Crustal Material}

437 Second source contributes to the entirety of Fe, Li and K. It also shows significant contribution to $438 \mathrm{Ca}, \mathrm{Ga}, \mathrm{Ni}, \mathrm{Na}$ and $\mathrm{Sr}$. Presence of high contributions to $\mathrm{Ca}$ and Fe would suggest that this source 439 is of crustal origin. As discussed in previous models, the mean contribution of this source to road 440 dust is greater during monsoon season due to wash off soil from sidewalks. Other sources like 441 brake wear and tire wear are washed away by rains during the summer where re-suspended dust is 
442 found to contribute more. Contribution from this source is least during summer season due to

443 contribution from resuspended dust and tire and brake wear as seen in Figure 5.

\section{4.3.3. Source 3: Resuspended Dust}

445 This source is found to contribute more to $\mathrm{Pb}, \mathrm{Rb}, \mathrm{Zn}, \mathrm{Cr}, \mathrm{Co}$, and $\mathrm{Al}$. Presence of these elements 446 suggests that this source is largely from re-suspended road dust. Like other models in this study, 447 contribution from this source is greater during summer season. MCR model shows no contribution 448 from this source during winter season. Contribution from this source is found to be greater at 449 locations that lack a paved sidewalk (Figure 5).

\subsection{Seasonal Variation of Sources}

451 Unmix, PMF and MCR-ALS models show that contribution of crustal materials to road dust is 452 found to be greater during monsoon season. Only PCA-MLRA model shows higher contribution 453 during summer season. Considering that PCA-MLRA model overestimates the contribution of this 454 single source considerably, the results obtained from it can be erroneous. The other three models 455 attribute lowest contribution to summer season. As mentioned in previous sections, this can be 456 attributed to increased tire and brake wear during summer season.

models. Drier road conditions during summer season can lead to increased resuspension of road 459 dust particles. Likewise, all four models identified that the contribution of resuspended road dust 460 is least during monsoon season owing to the wet deposition of resuspended dust when in contact 461 with rains.

Contribution of tire and brake wear is found to be nearly equal during summer and winter 463 seasons and lowest during monsoon seasons. Summer contribution is slightly higher due to 
464 increase in tire wear resulting from the higher road temperatures. Winter contributions are equally

465 high due to stable atmospheric conditions that are observed during winter months. Tire and brake

466 wear particles tend to be very small and hence can be easily washed away. This would explain the

467 low concentration during monsoon season.

Unmix is the only model that could identify contribution from vehicular emissions. This source shows high contribution during summer season. Winter and monsoon concentrations are nearly equal. Biomass combustion on the other hand have contradicting results from two models.

471 PMF model shows high contribution of biomass burning during summer season. This is the 472 expected result since biomass combustion is highly unlikely during monsoon season. However, 473 this anomaly is observed in PCA-MLRA. Presence of elements like Li and In in this source 474 suggests that the specific principal component is a combination of sources.

\subsection{Spatial Distribution of Sources}

The models identified six sources in total: crustal matter, re-suspended road dust, biomass combustion, tire and brake wear, vehicular emission and industrial. Of these sources, crustal matter and re-suspended road dust is identified by all the models. Tire wear, brake wear or a combination of both is identified by three models (Unmix, PCA and PMF). Two models (PCA and PMF) identified biomass as a source of pollution

480 in the region. Industrial source is identified by MCR-ALS model and vehicular emission is identified by

481 Unmix model. The spatial distribution of various sources quantified by the source apportionment models 482 are shown in Figure 6.

\section{[INSERT FIGURE 6]}

Crustal source is identified by all four receptor models. The PCA model placed the highest contribution on crustal source. Lowest contribution is apportioned by the PMF model. The PCA model 

matter (37\% to 62\%). Hot spots identified are along the main road (locations 15 and 16). The PMF model also shows similar hot spots. The contribution of crustal material according to the PMF model is considerably low compared to other models. MCR model showed the highest variance in contribution from 491 this source (between 65\% and 100\%). From Figure 3 and Figure 4, both PMF and Unmix models show 492 high contribution from crustal material during monsoon season. Higher contribution is noted in roads that 493 lack a paved sidewalk (locations 9, 10 and 13).

Re-suspended road dust is another source identified by all four receptor models. The contribution of resuspended road dust is estimated to be between $1 \%$ and $16 \%$. Highest contribution to the source is estimated by the PMF model. As per the PMF model, the contributions varied from $2 \%$ to $23 \%$. The highest contributions are noted at highways (locations 6 and 8). Lowest contribution is noted at Gandhinagar main road (location 17). Unmix model also identified location 8 as a hotspot for this source. Lowest mean contribution is obtained from the PCA model. Three of the four models show highest contribution from resuspended road dust during summer and lowest contribution during winter (Figures 2, 3 and 5). PCA apportioned the least contribution from resuspended dust during summer season. Figure 4 shows that PCA overestimated the contribution from crustal material in all three seasons.

Unmix model shows relatively high contribution for tire and brake wear (17\% to 44\%). Lowest contribution to this source is noted by the PCA model. Unmix and PMF models show high contribution of 505 tire and brake wear during summer season and lowest during monsoon season (Figure 2 and 3). Biomass combustion is identified by both PCA and PMF models. PMF model shows higher contribution for this source during summer season. PMF model apportioned negligible contribution form this source during monsoon season while PCA model apportioned highest contribution for this source during monsoon season.

509 The principal component representing contribution from biomass could be a composite of multiple sources.

510 Lowest biomass concentration is noted at lorry owner's association petrol pump (location 18). Vehicular 511 emission is identified in the Unmix model and Industrial source by MCR-ALS model. The industrial source 
512 is found to contribute higher towards the north of the city and vehicular emission towards the south of the

513 city. Summer season experiences highest contribution from this source and monsoon season the least.

514 Three receptor models (PMF, Unmix and PCA) identified five sources each, while MCR-

515 ALS can only identify three sources (Figure 5). The implementation of MCR-ALS model available

516 in CRAN is designed specifically for spectral analysis, which limits its use in cases where deviation

517 from ideal bilinear behavior is possible. The results from PCA model are unsatisfactory and

518 pollution from most of the sources are attributed to a single source (Crustal) for all three seasons

519 (Figure 4). A KMO sample adequacy of 0.56 is classified as miserable by Henry Kaiser. This

520 would suggest that although some information can be extracted by PCA, the model is ill suited for

521 the data at hand. PMF model did an admirable job in source apportionment of road dust with the

522 detriment that many locations during all three seasons had to be ignored due to them being outliers.

523 Though its performance characteristics are acceptable, the residuals for many species in PMF are

524 considerably greater than all other models in this study. Samples collected from different locations

525 can add uncertainty that is not addressed by PMF model. Of the four models tested, Unmix model

526 is found to give the best source apportionment result, with excellent performance characteristics

527 and lowest scaled residuals of the bunch.

\section{5. Conclusion}

529 Road dust is a significant source of PM in an urban environment. Source apportionment of road dust is thus

530 essential for effectively controlling urban air quality. Receptor models are some of the most robust

531 frameworks available for source apportionment. In this study, the source apportionment performance of

532 four receptor models viz. Unmix, PMF, PCA and MCR-ALS methods are studied and compared. Road dust

533 samples are collected form 18 sampling locations within the study region and analyzed using ICP-OES.

534 The resulting elemental composition data is then used for receptor modeling studies. 
Unmix model extracted five sources (resuspended dust, tire wear, brake wear, vehicular emission,

536 and crustal material). The PMF model also managed to extract five sources for road dust in the region

537 (vehicular emission, biomass combustion, resuspended dust, and crustal material). Although the PCA

538 method extracted five sources, two sources are found to be of the same composition. The four sources

539 classified by PCA model are crustal material, biomass burning, resuspended dust and vehicular emissions.

540 The MCR-ALS model identified an industrial source, crustal source, and resuspended dust. All four models

541 identified crustal material as the predominant source of road dust in the region. Of the four models tested,

542 UNMIX model is found to give the best results for this dataset.

544 study also brought forth the limitations of different receptor models when applied to road dust. Multivariate 545 receptor models can be immensely powerful tools for controlling and mitigating health effects from urban 546 road dust. More studies comparing the source apportionment performance of receptor models are thus 547 necessary.

\section{Declarations}

Jithin Jose: Conceptualization, Data curation, Methodology, Investigation, Formal Analysis,

551 Software, Validation, Visualization, Writing - original draft. B. Srimuruganandam: Project 552 administration, Conceptualization, Methodology, Resources, Supervision, Visualization, 553 Validation, Writing - review \& editing.

\section{$554 \quad$ Funding}

555 The authors have received no specific grant from funding agencies in the public, commercial, or not-for556 profit sectors for this research. 
The authors declare no conflict of interest.

\section{Acknowledgements}

561 We extend our sincere thanks to Dr. Bhaskar Das, Lab-in-charge, Environmental Engineering Laboratory,

562 School of Civil Engineering, Vellore Institute of Technology, Vellore for offering Microwave digestion

563 and ICP-OES facility. The authors have received no specific grant from funding agencies in the public,

564 commercial, or not-for-profit sectors for this research. The authors declare no conflict of interest.

565

566

567

568

569

570

571

572

573

574

575

576

577

578

579

580

581

582

583

584

585

586

587

588

589

590

Abu-Allaban M, Gillies JA, Gertler AW, et al (2003) Tailpipe, resuspended road dust, and brake-wear emission factors from on-road vehicles. Atmos Environ 37:5283-5293. https://doi.org/10.1016/j.atmosenv.2003.05.005

Achad M, Caumo S, de Castro Vasconcellos P, et al (2018) Chemical markers of biomass burning: Determination of levoglucosan, and potassium in size-classified atmospheric aerosols collected in Buenos Aires, Argentina by different analytical techniques. Microchem J 139:181-187. https://doi.org/10.1016/j.microc.2018.02.016

Al-Chalabi AS, Hawker D (1997) Response of vehicular lead to the presence of street dust in the Atmos Environ of major roads. Sci Total Environ 206:195-202. https://doi.org/10.1016/S00489697(97)80010-1

Amato F, Pandolfi M, Escrig A, et al (2009) Quantifying road dust resuspension in urban environment by Multilinear Engine: A comparison with PMF2. Atmos Environ 43:2770-2780. https://doi.org/10.1016/j.atmosenv.2009.02.039

Amato F, Querol X, Johansson C, et al (2010) A review on the effectiveness of street sweeping, washing and dust suppressants as urban PM control methods. Sci Total Environ 408:3070-3084. https://doi.org/10.1016/j.scitotenv.2010.04.025

Andreae MO (1983) Soot Carbon and Excess Fine Potassium: Long-Range Transport of CombustionDerived Aerosols. Science 220:1148-1151. https://doi.org/10.1126/science.220.4602.1148

Arslan H (2001) Heavy Metals in Street Dust in Bursa, Turkey. J of Trace and Microprobe Tech 19:439445. https://doi.org/10.1081/TMA-100105058

ASTM (2001) Standard Test Method for Sieve Analysis of Fine and Coarse Aggregates. In: Annual Book of ASTM Standards. ASTM, pp 1-5

Azid A, Juahir H, Ezani E, et al (2015) Identification Source of Variation on Regional Impact of Air Quality Pattern Using Chemometric. Aerosol Air Qual Res 15:1545-1558. https://doi.org/10.4209/aaqr.2014.04.0073 
591

592

593

594

595

596

597

598

599

600

601

602

603

604

605

606

607

608

609

610

611

612

613

614

615

616

617

618

619

620

621

622

623

624

625

626

627

628

629

630

631

632

Banerjee T, Murari V, Kumar M, Raju MP (2015) Source apportionment of airborne particulates through receptor modeling: Indian scenario. Atmos Res 164-165:167-187. https://doi.org/10.1016/j.atmosres.2015.04.017

Bartkowiak A, Dabkovska-Naskret H, Lemanowicz J, Siwik-Ziomek A (2017) Assessment of physiochemical and biological factors of urban street dust. Environ Prot Eng 43:155-164. https://doi.org/10.5277/epe170310

Belis CA, Larsen BR, Amato F, et al (2014) European Guide on Air Pollution Source Apportionment with Receptor Models JRC Reference Report. European Union doi: http://dx doi org/102788/9332

Councell TB, Duckenfield KU, Landa ER, Callender E (2004) Tire-Wear Particles as a Source of Zinc to the Environment. Environ Sci Technol 38:4206-4214. https://doi.org/10.1021/es034631f

Das A, Krishna KVSS, Kumar R, et al (2018) Lead isotopic ratios in source apportionment of heavy metals in the street dust of Kolkata, India. Int $\mathrm{J}$ Environ Sci Technol 15:159-172. https://doi.org/10.1007/s13762-017-1377-0

Devi NL, Yadav IC (2018) Chemometric evaluation of heavy metal pollutions in Patna region of the Ganges alluvial plain, India: implication for source apportionment and health risk assessment. Environ Geochem Hlth 40:2343-2358. https://doi.org/10.1007/s10653-018-0101-4

Fulton WS (2005) Steel Tire Cord-Rubber Adhesion, Including the Contribution of Cobalt. Rubber Chemistry and Technology 78:426-457. https://doi.org/10.5254/1.3547891

Galbreath KC, Toman DL, Zygarlicke CJ, et al (2000) Nickel Speciation of Residual Oil Fly Ash and Ambient Particulate Matter Using X-ray Absorption Spectroscopy. J Air Waste Manag Assoc 50:1876-1886. https://doi.org/10.1080/10473289.2000.10464230

Garg BD, Cadle SH, Mulawa PA, et al (2000) Brake Wear Particulate Matter Emissions. Environ Sci \& Technol 34:4463-4469. https://doi.org/10.1021/es001108h

Glover I (1966) The Fuel Additive Approach Towards the Alleviation of the Nuisance of Diesel Smoke. The Institute of Petroleum

Gramstat S (2018) Chapter 10 - Technological Measures for Brake Wear Emission Reduction: Possible Improvement in Compositions and Technological Remediation: Cost Efficiency. Non-Exhaust Emissions 205-227. https://doi.org/10.1016/B978-0-12-811770-5.00010-8

Habibi Kamran (1970) Characterization of particulate lead in vehicle exhaust-experimental techniques. Environ Sci Technol 4:239-248. https://doi.org/10.1021/es60038a001

Henry RC (1991) Multivariate receptor models. Elsevier Science Publishers, Amsterdam

Henry RC (2003) Multivariate receptor modeling by N-dimensional edge detection. Chemom Intell Lab Syst 65:179-189. https://doi.org/10.1016/S0169-7439(02)00108-9

Henry RC, Lewis CW, Hopke PK, Williamson HJ (1984) Review of receptor model fundamentals. Atmos Environ (1967) 18:1507-1515. https://doi.org/10.1016/0004-6981(84)90375-5

Heo J-B, Hopke PK, Yi SM (2009) Source apportionment of PM 2.5 in Seoul, Korea. Atmospheric Chem Phys 9:4957-4971. https://doi.org/10.5194/acp-9-4957-2009

Hermant M, Basset D, Razet JC (1986) Lubricant compositions containing calcium and barium fluorides

Hilden DL, Bergin SP (1986) The Effect of Manganese Fuel Additive and Exhaust Gas Recirculation on Diesel Particulate Emissions. SAE Transactions 95:250-269. https://doi.org/10.4271/860621

Hopke PK (2016) Review of receptor modeling methods for source apportionment. J Air Waste Manag Assoc 66:237-259. https://doi.org/10.1080/10962247.2016.1140693 
642

643

644

645

646

647

648

649

650

651

652

653

654

655

656

657

658

659

660

661

662

663

664

665

666

667

668

669

670

671

672

673

674

IARC (2020) List of Classifications - IARC Monographs on the Identification of Carcinogenic Hazards to Humans. https://monographs.iarc.fr/list-of-classifications. Accessed 13 May 2020

Isaac CPJ, Sivakumar A, Kumar CRP (2012) Lead levels in breast milk, blood plasma and intelligence quotient: a health hazard for women and infants. Bull environ contam toxicol 88:145-149

Johnson TM, Guttikunda S, et al (2011) A Review of Top-down Source Apportionment Techniques and Their Application in Developing Countries. The World Bank Group.

Jose J, Srimuruganandam B (2020) Investigation of road dust characteristics and its associated health risks from an urban environment. Environ Geochem Hlth. https://doi.org/10.1007/s10653-020-00521-6

Khpalwak W, Jadoon WA, Abdel-dayem SM, Sakugawa H (2019) Polycyclic aromatic hydrocarbons in urban road dust, Afghanistan: Implications for human health. Chemosphere 218:517-526. https://doi.org/10.1016/j.chemosphere.2018.11.087

Konstandopoulos AG, Gratz LD, Johnson JH, et al (1988) Ceramic Particulate Traps for Diesel Emissions Control — Effects of a Manganese-Copper Fuel Additive. SAE Trans 97:37-53

Kukutschová J, Filip P (2018) Chapter 6 - Review of Brake Wear Emissions: A Review of Brake Emission Measurement Studies: Identification of Gaps and Future Needs. Non-Exhaust Emissions 123-146. https://doi.org/10.1016/B978-0-12-811770-5.00006-6

Kupiainen KJ, Tervahattu H, Räisänen M, et al (2005) Size and Composition of Airborne Particles from Pavement Wear, Tires, and Traction Sanding. Environ Sci Technol 39:699-706. https://doi.org/10.1021/es035419e

Lakshminarayanan PA, Nayak NS (2011) Critical Component Wear in Heavy Duty Engines. John Wiley \& Sons

Mao Y, Wilson JD, Kort J (2013) Effects of a shelterbelt on road dust dispersion. Atmos Environ 79:590598. https://doi.org/10.1016/j.atmosenv.2013.07.015

Marín MRP, Gil EP, Blázquez LC, Capelo-Martínez JL (2011) Determination of trace and major elemental profiles in street dust samples by fast miniaturized ultrasonic probe extraction and ICP-MS. Talanta 84:840-845. https://doi.org/10.1016/j.talanta.2011.02.012

MHRD (2015) Re classification of cities/towns on the basis of census-2011 for the purpose of grant of HRA to central government. New Delhi

Miguel AG, Cass GR, Glovsky MM, Weiss J (1999) Allergens in Paved Road Dust and Airborne Particles. Environ Sci Technol 33:4159-4168. https://doi.org/10.1021/es9904890

Monaci F, Bargagli R (1997) Barium and Other Trace Metals as Indicators of Vehicle Emissions. Water Air Soil Poll 100:89-98. https://doi.org/10.1023/A:1018318427017

Monaci F, Moni F, Lanciotti E, et al (2000) Biomonitoring of airborne metals in urban environments: new tracers of vehicle emission, in place of lead. Environ Poll 107:321-327. https://doi.org/10.1016/S0269-7491(99)00175-X

Ooij WJ van (1984) Mechanism and Theories of Rubber Adhesion to Steel Tire Cords-An Overview. Rubber Chem Technol 57:421-456. https://doi.org/10.5254/1.3536016

Paatero P, Tapper U (1994) Positive matrix factorization: A non-negative factor model with optimal utilization of error estimates of data values. Environmetrics 5:111-126. https://doi.org/10.1002/env.3170050203

Pant P, Harrison RM (2012) Critical review of receptor modelling for particulate matter: A case study of India. Atmos Environ 49:1-12. https://doi.org/10.1016/j.atmosenv.2011.11.060 
675

676

677

678

679

680

681

682

683

684

685

686

687

688

689

690

691

692

693

694

695

696

697

698

699

700

701

702

703

704

705

706

707

708

709

710

711

712

713

714

715

Peltier RE, Hsu S-I, Lall R, Lippmann M (2009) Residual oil combustion: a major source of airborne nickel in New York City. J Expo Sci Environ Epidemiol 19:603-612. https://doi.org/10.1038/jes.2008.60

Pio CA, Legrand M, Alves CA, et al (2008) Chemical composition of atmospheric aerosols during the 2003 summer intense forest fire period. Atmos Environ 42:7530-7543. https://doi.org/10.1016/j.atmosenv.2008.05.032

Rastegar F, Craft AE (1993) Piston ring coatings for high horsepower diesel engines. Surf Coat Technol 61:36-42. https://doi.org/10.1016/0257-8972(93)90199-X

Rudnick RL, Shaner A, Portillo K (2019) Top 5 elements in the upper crust of Earth. Top five elements in the upper crust of Earth

Sharma R, Pervez S (2003) Enrichment and Exposure of Particulate Lead in a Traffic Environment in India. Environ Geochem Hlth 25:297-306. https://doi.org/10.1023/A:1024520522083

Tauler R, Viana M, Querol X, et al (2009) Comparison of the results obtained by four receptor modelling methods in aerosol source apportionment studies. Atmos Environ 43:3989-3997. https://doi.org/10.1016/j.atmosenv.2009.05.018

Taylor SR (1964) Abundance of chemical elements in the continental crust: a new table. Geochim Cosmochim Acta 28:1273-1285. https://doi.org/10.1016/0016-7037(64)90129-2

Testa SM (2004) Sources of Chromium Contamination in Soil and Groundwater. In: Chromium(VI) Handbook. CRC Press

Thomaidis NS, Bakeas EB, Siskos PA (2003) Characterization of lead, cadmium, arsenic and nickel in PM2.5 particles in the Athens atmosphere, Greece. Chemosphere 52:959-966. https://doi.org/10.1016/S0045-6535(03)00295-9

Thorpe A, Harrison RM (2008) Sources and properties of non-exhaust particulate matter from road traffic: A review. Sci Total Environ 400:270-282. https://doi.org/10.1016/j.scitotenv.2008.06.007

Thurston GD, Spengler JD (1985) A multivariate assessment of meteorological influences on inhalable particle source impacts. J Clim Appl Meteorol 24:1245-1256

Truex TJ, Pierson WR, McKee DE, et al (1980) Effects of barium fuel additive and fuel sulfur level on diesel particulate emissions. Environ Sci Technol 14:1121-1124

Turekian KK, Wedepohl KH (1961) Distribution of the Elements in Some Major Units of the Earth's Crust. GSA Bull 72:175-192. https://doi.org/10.1130/0016-7606(1961)72[175:DOTEIS]2.0.CO;2

U.S. EPA O (1996) EPA Method 3050B: Acid Digestion of Sediments, Sludges, and Soils

Wang C-F, Chang C-Y, Tsai S-F, Chiang H-L (2005) Characteristics of Road Dust from Different Sampling Sites in Northern Taiwan. J Air Waste Manag Assoc 55:1236-1244. https://doi.org/10.1080/10473289.2005.10464717

Xie M, Teresa LC, et al. Intra-Urban Spatial Variability and Uncertainty Assessment of PM2.5 Sources Based on Carbonaceous Species. Atmos Environ 60:305-15. https://doi.org/10.1016/j.atmosenv.2012.06.036.

Yaroshevsky AA (2006) Abundances of chemical elements in the Earth's crust. Geochem Int 44:48-55. https://doi.org/10.1134/S001670290601006X

Yasuda T, Kondo H, Echigo Y, et al (1990) Rubber compositions for tires

Yu J, Yan C, Liu Y, et al (2018) Potassium: A Tracer for Biomass Burning in Beijing? Aerosol Air Qual Res 18:2447-2459. https://doi.org/10.4209/aaqr.2017.11.0536 
716

717

718

719

720

721

722

723

724

725

726

727

728

729

730

731

732

733

734

735

736

3

29

31

32

Zeng X, Xu X, Qin Q, et al (2019) Heavy metal exposure has adverse effects on the growth and development of preschool children. Environ Geochem Hlth 41:309-321. https://doi.org/10.1007/s10653-018$0114-\mathrm{z}$

Zhang Y, Cai J, Wang S, et al (2017) Review of receptor-based source apportionment research of fine particulate matter and its challenges in China. Sci Total Environ 586:917-929. https://doi.org/10.1016/j.scitotenv.2017.02.071

4

5

6

7

8

30 


\section{Figures}

Figure 1: Sampling locations

Figure 2: Source contribution in study locations (above) and source contribution by elements (below) from the Unmix model

Figure 3: Source contribution in study locations (above) and source contribution by elements (below) from the PMF model

Figure 4: Source contribution in study locations (above) and source contribution by elements (below) from the PCA model

Figure 5: Source contribution in study locations (above) and source contribution by elements (below) from the MCR model

Figure 6: Distribution of sources in the study region. Lines represent the contribution of individual sources as calculated by different receptor models. Map on the right shows the different sampling locations. Explanation of sampling locations is provided in Table 1. (units in \% contribution)

\section{Tables}

Table 1: List of sampling locations

753 Table 2: Principal component scores from PCA analysis (significant values are in bold)

\section{Supplementary Tables}

755 Table S1: Mean and SD of elements from input data (Generated by Unmix model)

756 Table S2: Unmix Source composition (units in $\mathrm{mg} / \mathrm{kg}$ )

757 Table S3: Unmix Source contribution (units in $\mathrm{mg} / \mathrm{kg}$ ) 
758 Table S4: Correlation between unmix models

759 Table S5: Scaled residuals from Unmix model

760 Table S6: PMF Source contribution (no contribution shown by -999)

761 Table S7: PMF Source composition (units in $\mathrm{mg} / \mathrm{kg}$ )

762 Table S8: Source contribution from PCA model

763 Table S9: Source loading from MCR-ALS

764 Table S10: Source contribution from MCR-ALS

765 Table S11: Scaled residuals from MCR-ALS model

766 Table S12: Residuals for PMF model 
Figures

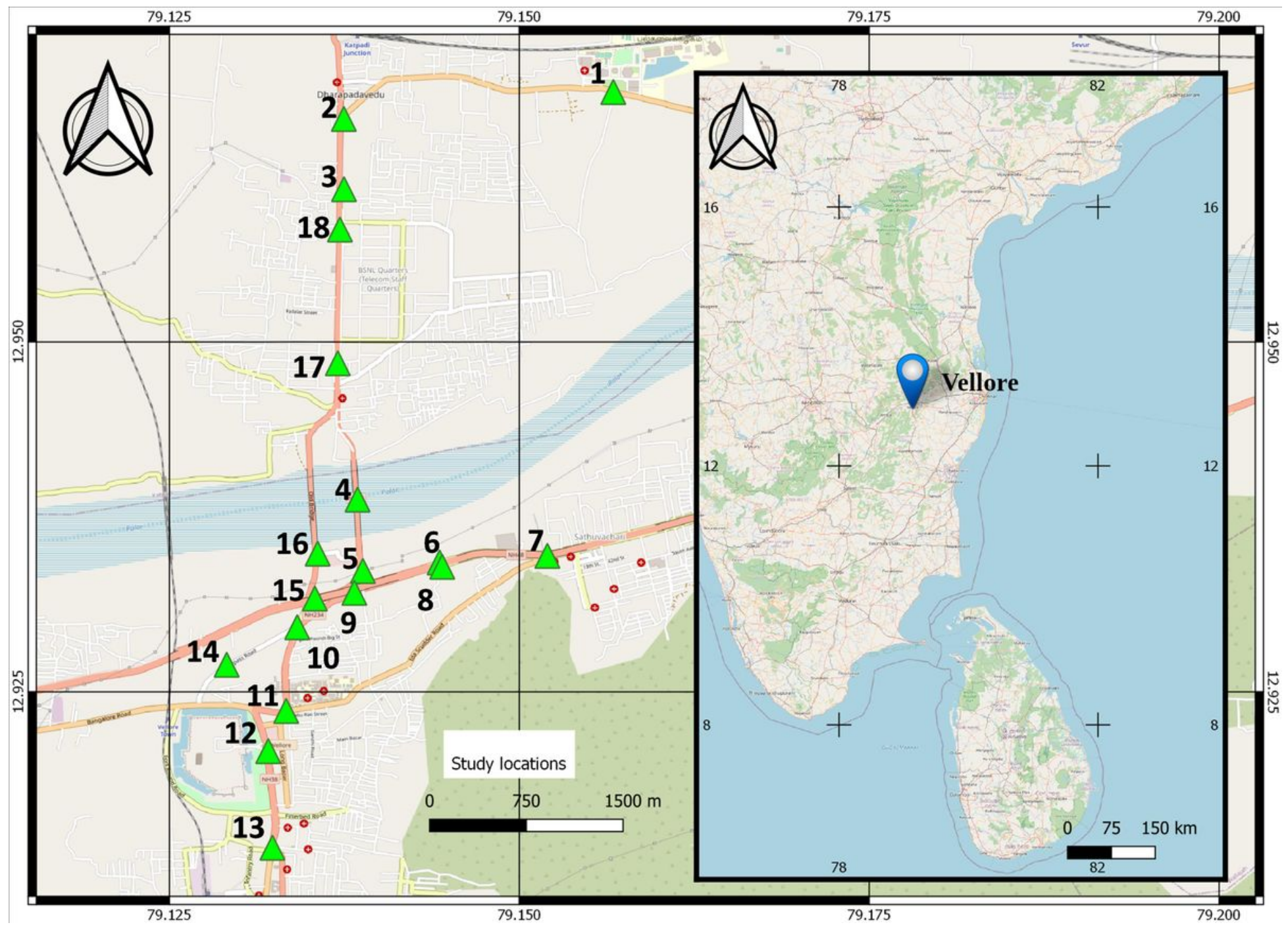

Figure 1

Sampling locations 

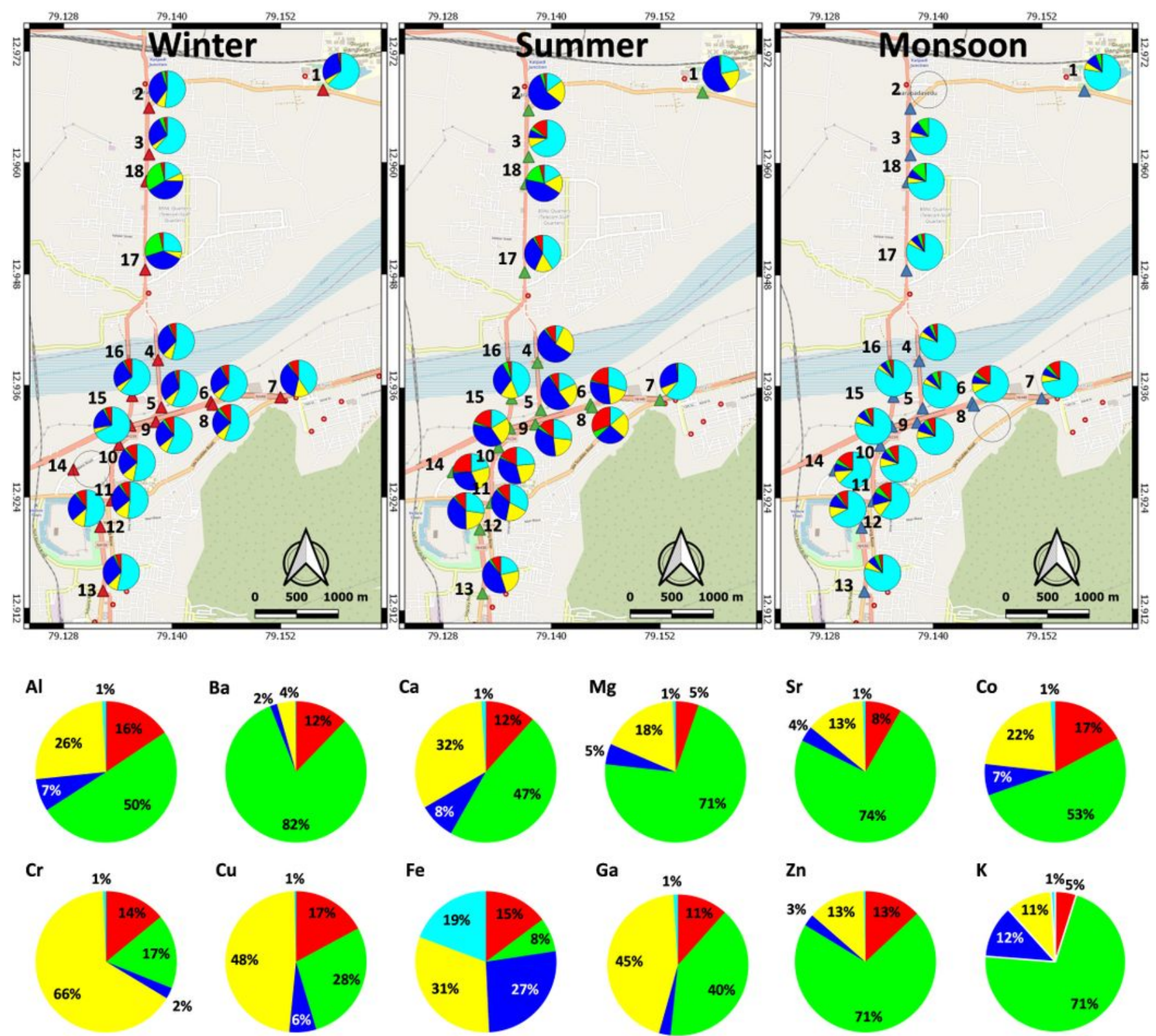

Ga
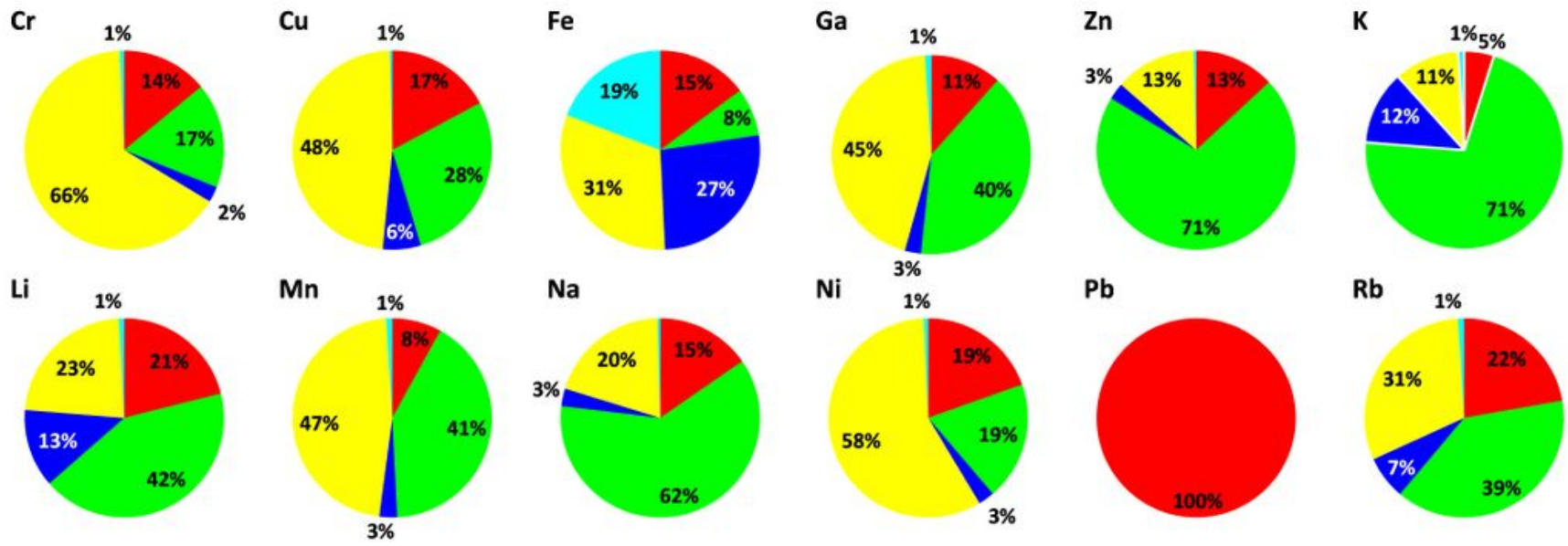

Ni $\quad 1 \%$
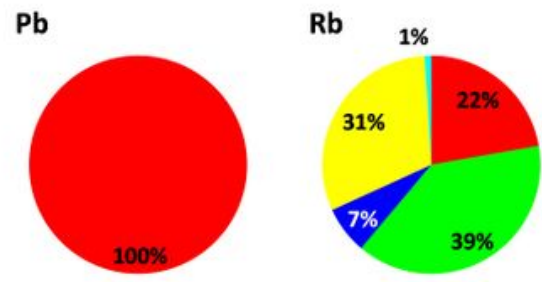

Source 1

Source 2

Source 3

Source 4

Source 5

Figure 2

Source contribution in study locations (above) and source contribution by elements (below) from the Unmix model 


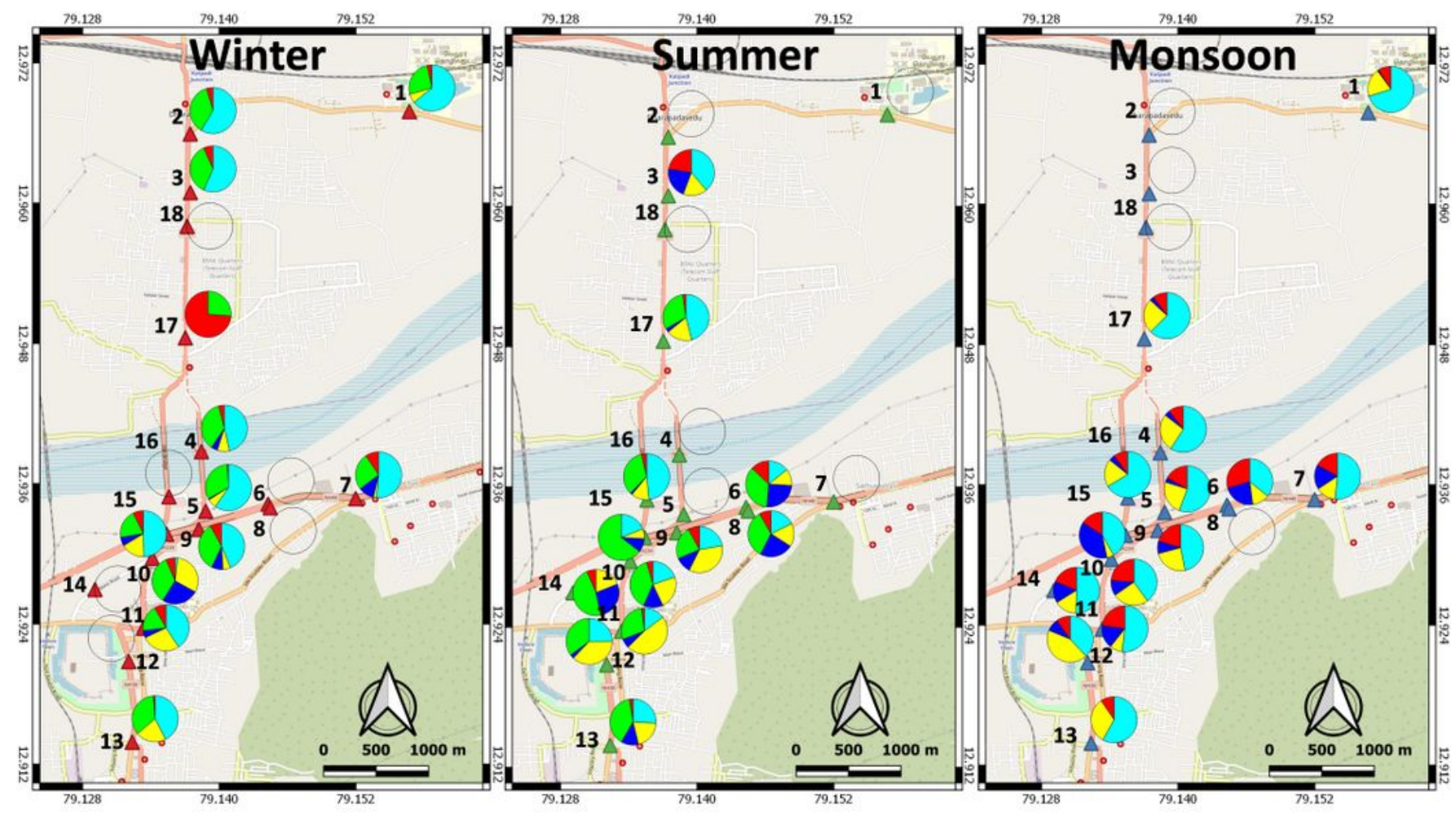

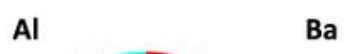
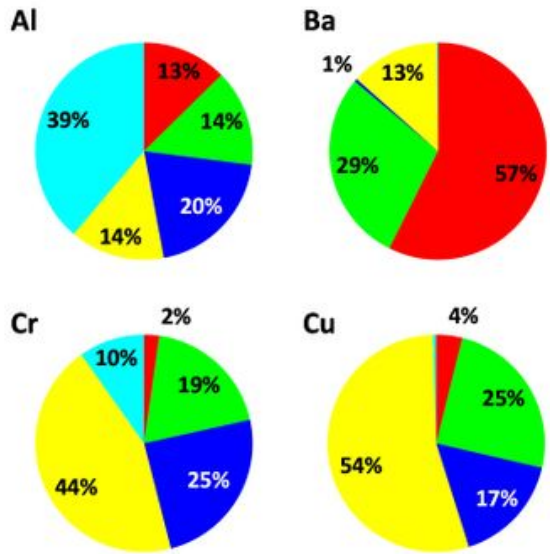

$\mathrm{Cu}$
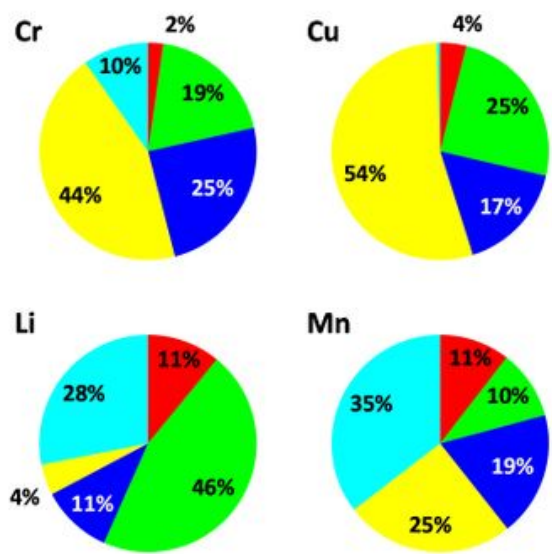

$\mathrm{Ca}$
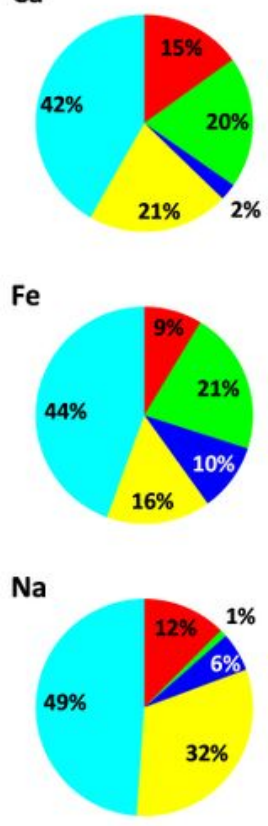

Source 2

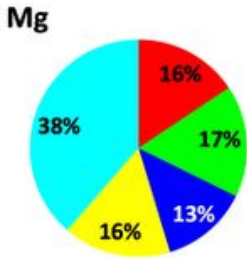

$\mathrm{Sr}$

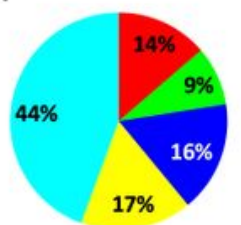

Ga

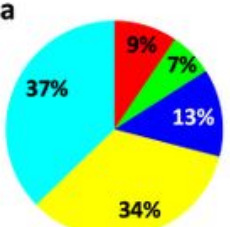

$\mathrm{Ni}$
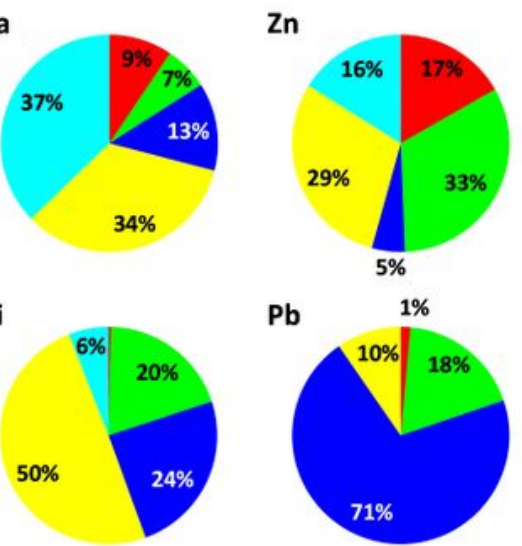

Co

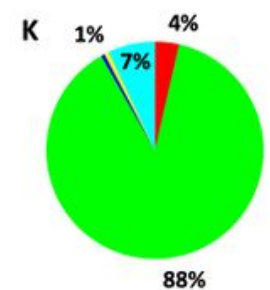

Rb

Source 4
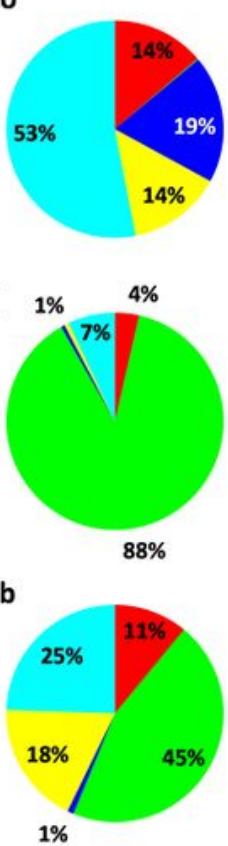

Source 5

Figure 3

Source contribution in study locations (above) and source contribution by elements (below) from the PMF model 

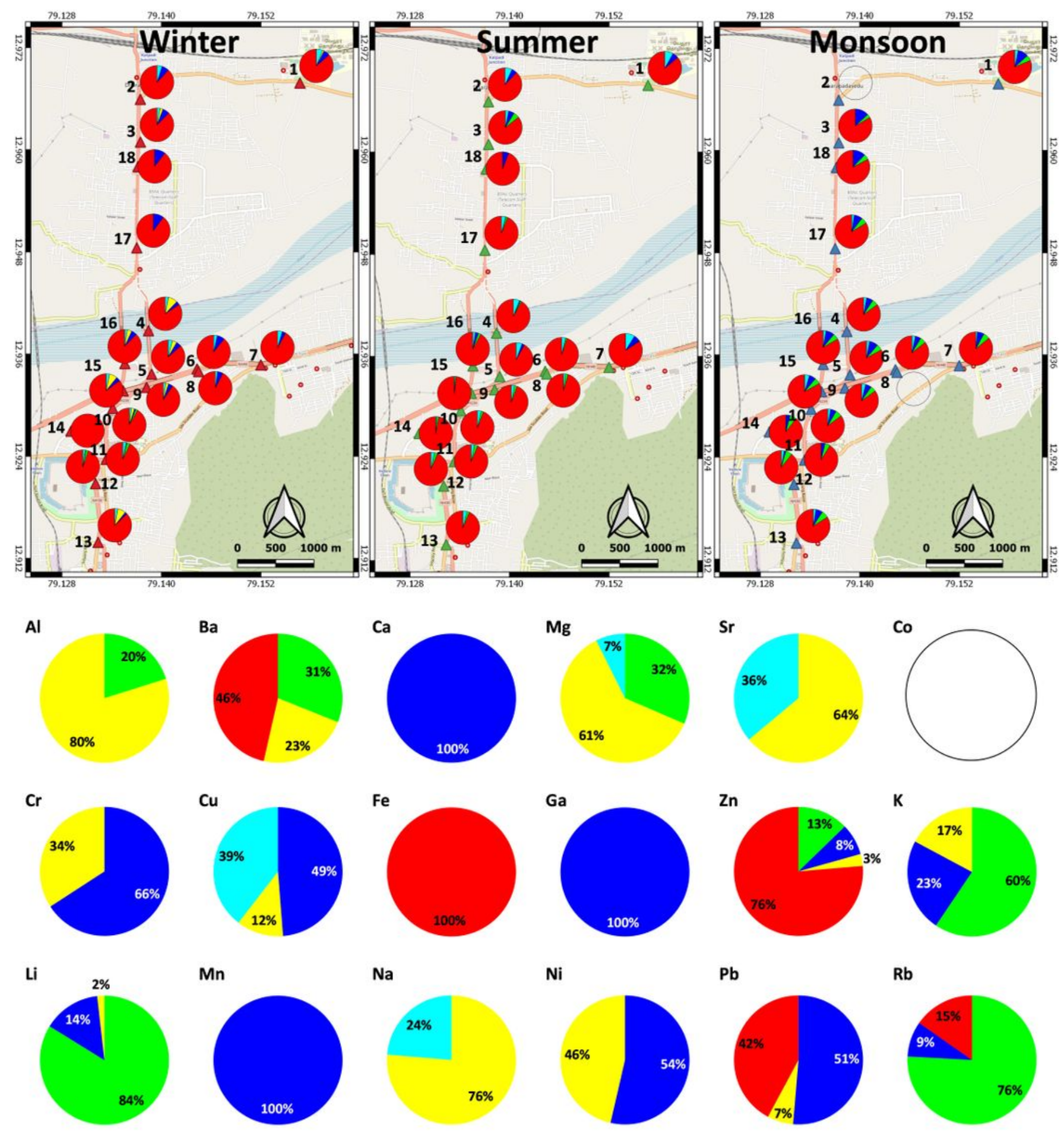

$\mathrm{Na}$

Ni

Pb

Rb
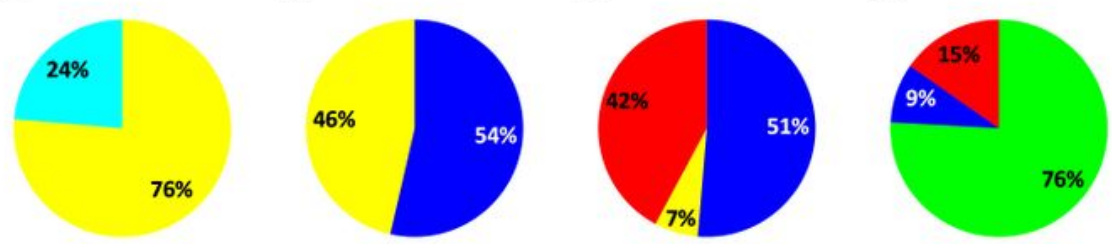

Source 1

Source 2

Source 3

Source 4

Source 5

Figure 4

Source contribution in study locations (above) and source contribution by elements (below) from the PCA model 


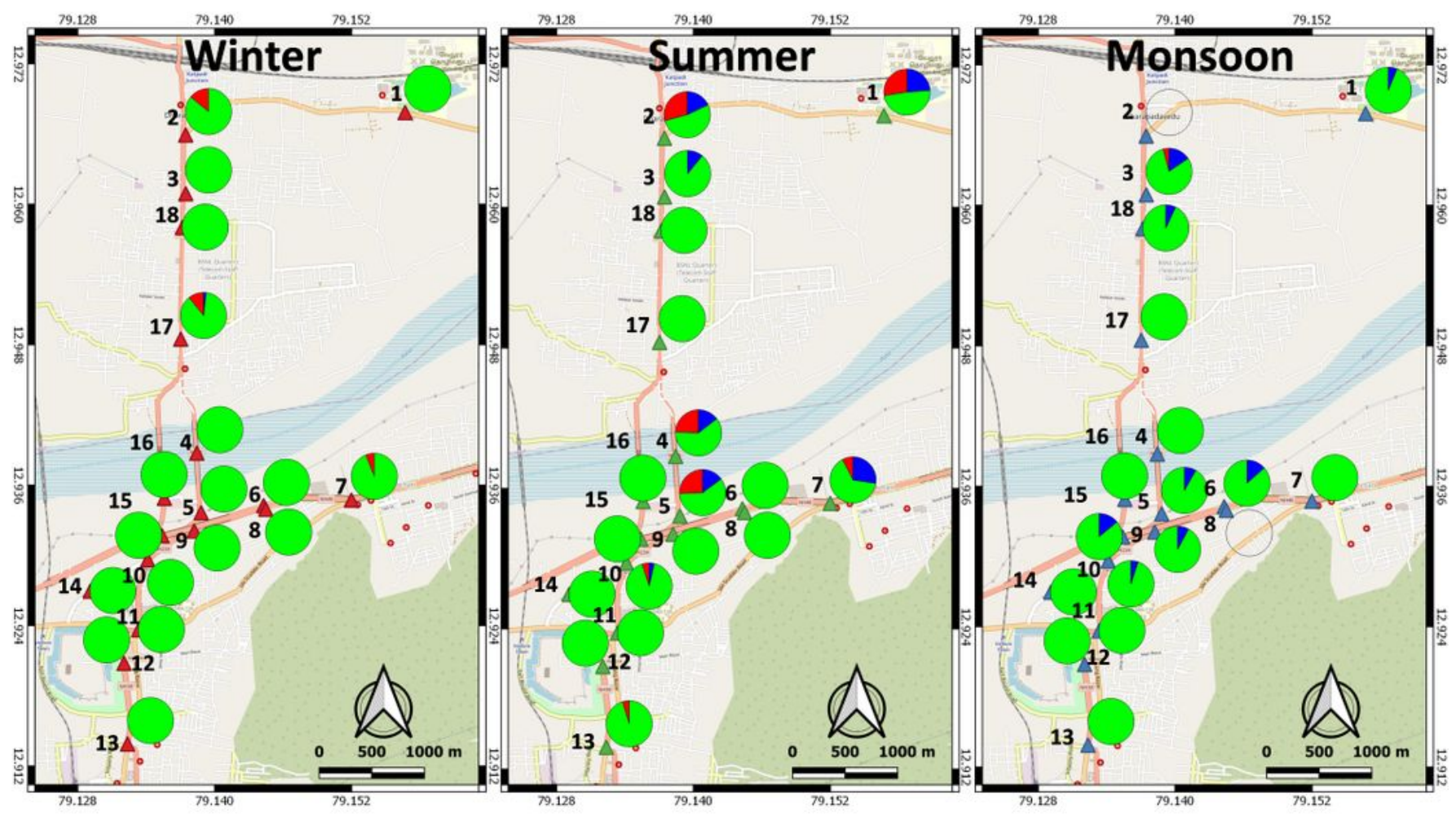

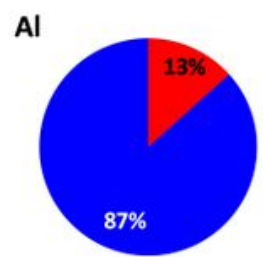

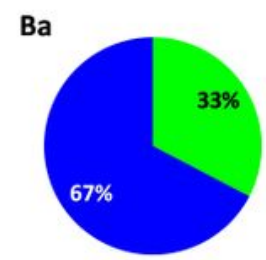

$\mathrm{Ca}$
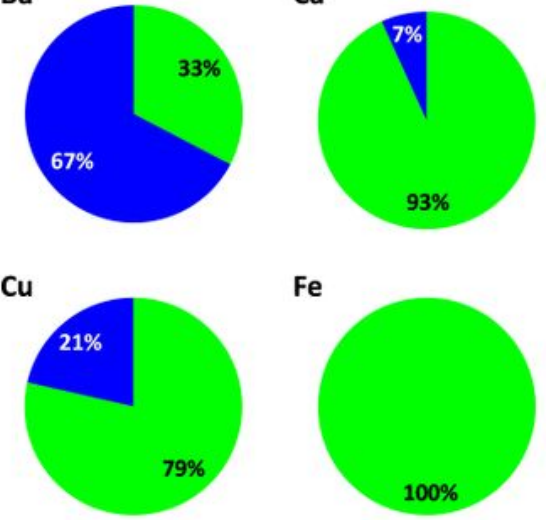

Li

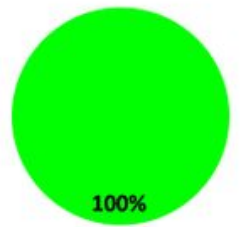

Mn

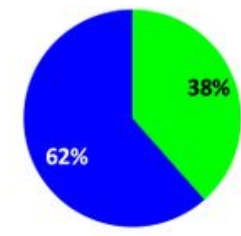

$\mathrm{Fe}$

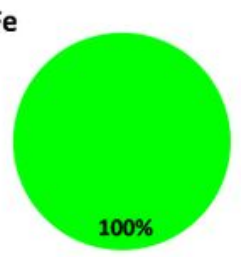

$\mathrm{Na}$

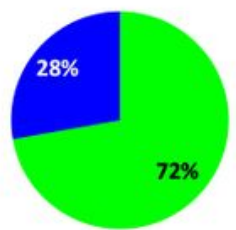

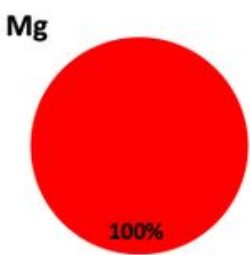

Ga

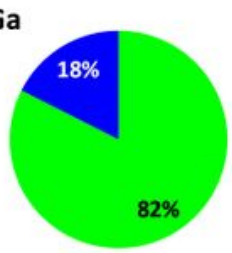

Ni

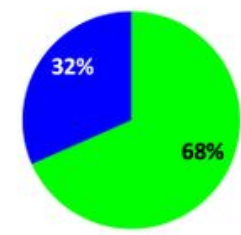

Source 2

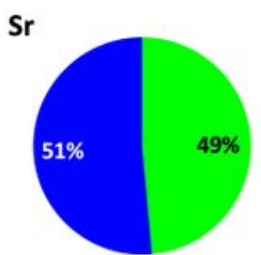

Co

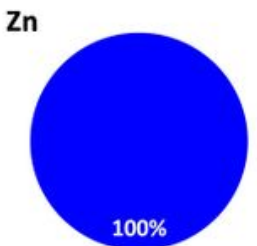

$\mathrm{Pb}$

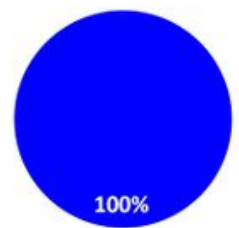

K

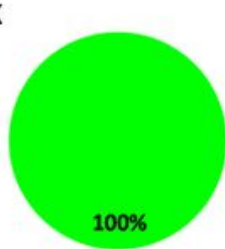

$\mathbf{R b}$

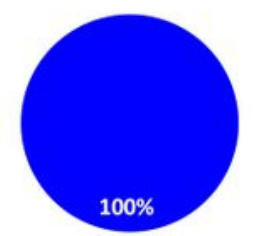

Source 1

Source 3

Figure 5

Source contribution in study locations (above) and source contribution by elements (below) from the MCR model 


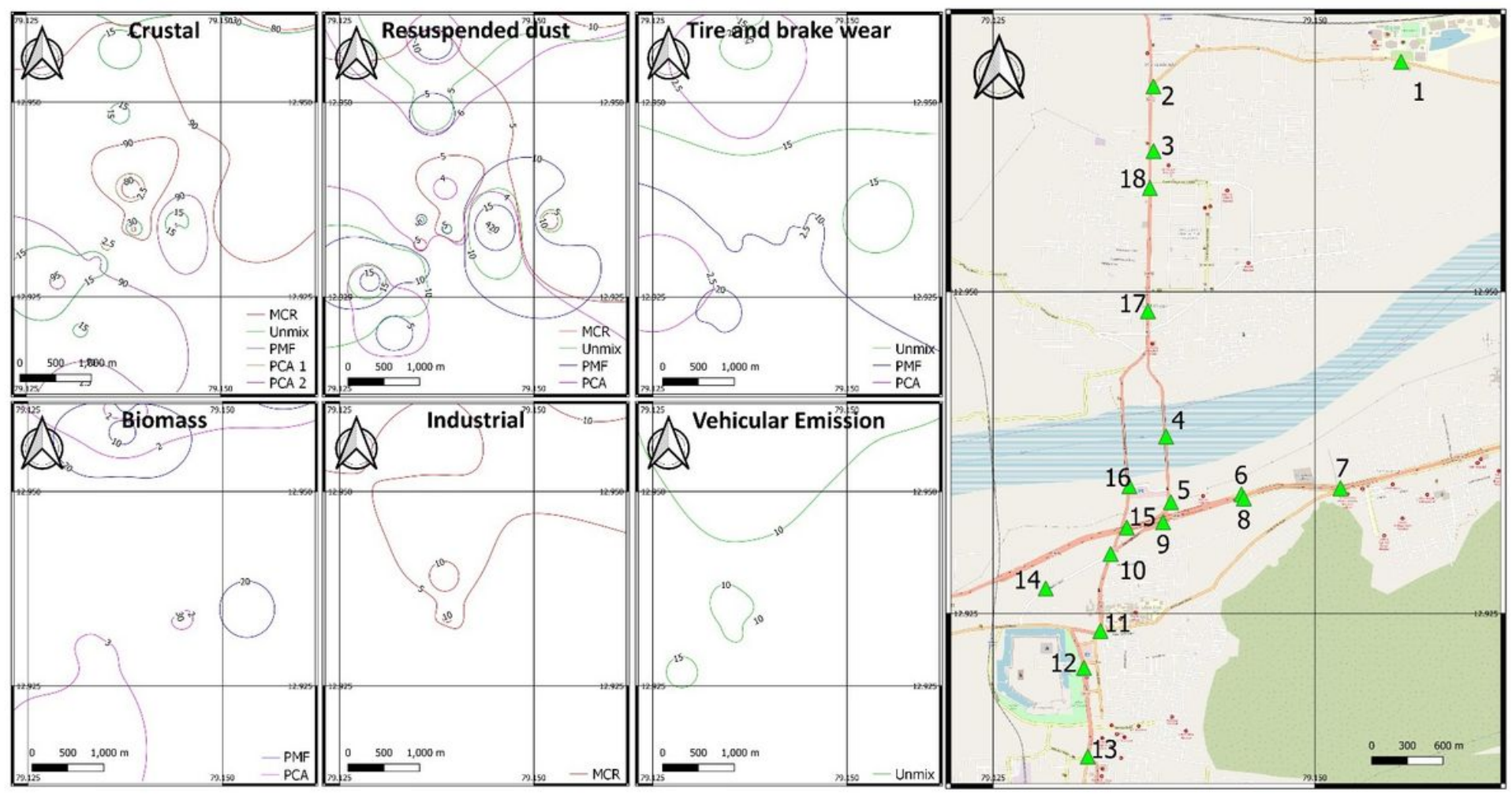

Figure 6

Distribution of sources in the study region. Lines represent the contribution of individual sources as calculated by different receptor models. Map on the right shows the different sampling locations. Explanation of sampling locations is provided in Table 1. (Units in \% contribution)

\section{Supplementary Files}

This is a list of supplementary files associated with this preprint. Click to download.

- TableS1.docx

- Tables2.docx

- TableS3.docx

- TableS4.docx

- TableS5.docx

- TableS6.docx

- TableS7.docx

- TableS8.docx

- TableS9.docx

- TableS10.docx

- Tables11.docx 
- TableS12.docx 